\title{
Endovascular repair of an aorto-iliac aneurysm succeeded by kidney transplantation
}

\author{
Tratamento endovascular de aneurisma aorto-ilíaco sucedido por transplante renal
}

Marcelo Bellini Dalio', Matheus Bredarioli², Edwaldo Edner Joviliano 3 , Jesualdo Cherri ${ }^{3}$, Haylton Jorge Suaid ${ }^{3}$, Carlos Eli Piccinato ${ }^{4}$

\begin{abstract}
We present the case of aorto-iliac aneurysm in a patient with chronic renal failure requiring dialysis who were treated with an endovascular stent graft and, later on, submitted to kidney transplantation. A 53-year-old male with renal failure requiring dialysis presented with an asymptomatic abdominal aorto-iliac aneurysm measuring $5.0 \mathrm{~cm}$ of diameter. He was treated with endovascular repair technique, being used an endoprosthesis Excluder. After four months, he was successfully submitted to kidney transplantation (dead donor), with anastomosis of the graft renal artery in the external iliac artery distal to the endoprosthesis. The magnetic resonance imaging, carried out 30 days after the procedure, showed a good positioning of the endoprosthesis and adequate perfusion of the renal graft. In the follow-up, the patient presented improvement of nitrogenous waste, good positioning of the endoprosthesis without migration or endoleak. The endovascular repair of aorto-iliac aneurysm in a patient with end-stage renal failure under hemodialysis treatment showed to be feasible, safe and efficient, as it did not prevent the success of the posterior kidney transplantation.
\end{abstract}

Keywords: Aortic aneurysm; iliac aneurysm; blood vessel prosthesis; kidney transplantation.

\section{Resumo}

Apresentamos o caso de aneurisma aortoilíaco em um paciente com insuficiência renal crônica dialítica tratado com uma endoprótese vascular, sendo, após, submetido a transplante renal. Um homem de 53 anos com insuficiência renal dialítica apresentava um aneurisma abdominal aortoilíaco assintomático com 5,0cm de diâmetro. Foi tratado com técnica endovascular com uma endoprótese Excluderâ. Após quatro meses, foi submetido a transplante renal (doador cadáver) com sucesso, com anastomose da artéria renal do enxerto na artéria ilíaca externa distal à endoprótese. A ressonância magnética 30 dias após o procedimento mostrou a endoprótese bem posicionada e o enxerto renal bem perfundido. No seguimento, o paciente evoluiu com melhora das escórias nitrogenadas, bom posicionamento da endoprótese, sem migração ou endoleak. O reparo endovascular do aneurisma aortoilíaco em paciente com insuficiência renal terminal em hemodiálise mostrou-se exequível, seguro e eficaz, e não comprometeu o sucesso do transplante renal posterior.

Palavras-chave: Aneurisma aórtico; aneurisma ilíaco; prótese vascular; transplante de rim.

\section{Introduction}

Treatment of patients with aorto-iliac aneurysm associated with chronic renal failure (CRF) under hemodialysis is a challenge, due to increased morbimortality ${ }^{1,2}$. Several authors reviewed open aneurysm repair in association with kidney transplantation (RT) and proposed a staged approach with aorto-iliac disease being treated first ${ }^{3-5}$. Endovascular aneurysm repair (EVAR) has been replacing open repair in patients with a high surgical risk, with the advantages of less morbimortality and shorter operative time and hospital stay ${ }^{6}$.

There are several reports of successfully EVAR performed in $\mathrm{RT}$ recipients ${ }^{7-9}$, but there are just two reported cases of EVAR followed by successful RT ${ }^{10,11}$. These were performed on aortic aneurysms. There are no reported cases of aorto-iliac aneurysm.

This paper reported a case of aorto-iliac aneurysm in a patient with CRF under hemodialysis successfully corrected by EVAR succeeded by RT.

Department of Surgery and Anatomy of Ribeirão Preto Medical School of Universidade de São Paulo (USP), Ribeirão Preto (SP), Brazil.

${ }^{1}$ PhD; Vascular and Endovascular Surgeon of Department of Surgery and Anatomy of Ribeirão Preto Medical School of Universidade de São Paulo (USP), Ribeirão Preto (SP), Brazil.

${ }^{2}$ Vascular and Endovascular Surgeon of Department of Surgery and Anatomy of Ribeirão Preto Medical School of Universidade de São Paulo (USP), Ribeirão Preto (SP), Brazil.

${ }^{3}$ PhD; Associate Professor of Department of Surgery and Anatomy of Ribeirão Preto Medical School of Universidade de São Paulo (USP), Ribeirão Preto (SP), Brazil.

${ }^{4}$ PhD; Titular Professor of Department of Surgery and Anatomy of Ribeirão Preto Medical School of Universidade de São Paulo (USP), Ribeirão Preto (SP), Brazil.

No conflicts of interest declared concerning the publication of this article

Manuscript received February $11^{\text {th }}$ 2010, accepted for publication March $22^{\text {nd }} 2010$

J Vasc Bras. 2010;9(3):164-167. 


\section{Case report}

A 53-year-old man presenting with end-stage CRF secondary to hypertensive nephrosclerosis treated with hemodialysis. He did not present diabetes mellitus, but had a 40-year smoking history. His bilateral limb pulses were palpable and symmetric. He referred an asymptomatic abdominal mass, and an investigation with computed tomography (CT) scan revealed an infrarenal aortic aneurysm $(5.0 \mathrm{~cm}$ transverse diameter), extending to both common iliac arteries $(3.0 \mathrm{~cm}$ transverse diameter each) until its bifurcations (Figure1). He underwent EVAR through bilateral groin incisions, with placement of an Excluder ${ }^{\circledR}$ endoprosthesis (W. L. Gore \& Associates, Flagstaff, Arizona) with the following measures:

- right main trunk $31 \mathrm{~mm} / 14 \mathrm{~mm} / 15 \mathrm{~cm}$;

- left contralateral leg $16 \mathrm{~mm} / 14 \mathrm{~mm} / 14 \mathrm{~cm}$;

- right extension $16 \mathrm{~mm} / 10 \mathrm{~mm} / 7 \mathrm{~cm}$;

- left extension $16 \mathrm{~mm} / 14 \mathrm{~mm} 7 \mathrm{~cm}$.

In order to completely exclude the aneurysm, both hypogastric artery orifices were covered by the extensions.

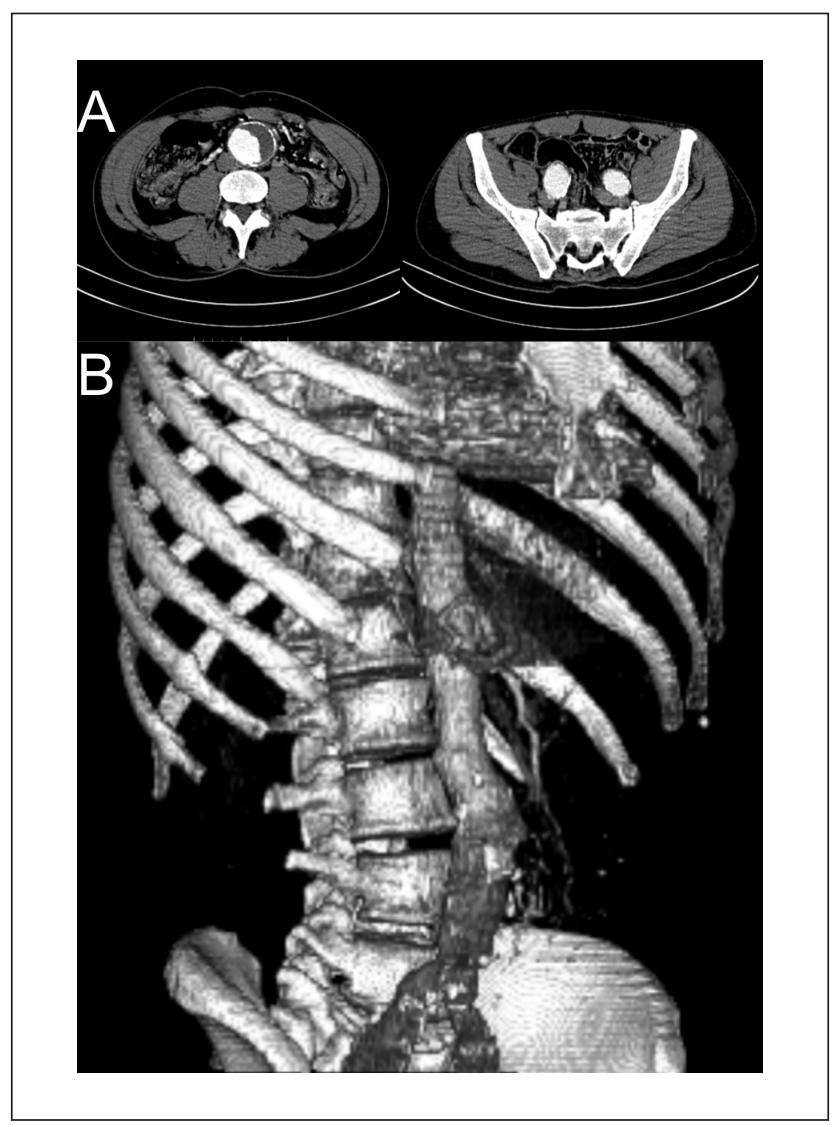

Figure 1 - Pre-EVAR axial (A) and 3D reconstruction (B) CT scan.
No embolization coils were used. Completion angiogram showed adequate positioning of the endograft and no endoleak. He made a good recovery and, beside some transient thigh paresthesia, no complications were observed. Postoperative rectosigmoidoscopy showed no signs of bowel ischemia. The patient went on hemodialysis on the day after and was discharged three days after the procedure. One-month CT scan showed good graft positioning and no endoleak (Figure 2).

Four months after EVAR, he underwent RT. Through a right Gibson incision; he received a left cadaveric renal transplant with HLA matching A0B1DR2 and negative crossmatch. The gratf had two arteries on a Carrel patch, single vein and single ureter. At dissection, it was possible to palpate the endograft in the right external iliac artery, which had a normal aspect and pulse at its distal portion. No retroperitoneal fibrosis or inflammation was observed. The transplant arterial patch was sutured in the right external iliac artery $0, .5 \mathrm{~cm}$ proximal to inguinal ligament by an end to side anastomosis using continuous polypropilene 6-0. The venous anastomosis was performed end-to-side in the external iliac vein using continuous polypropilene

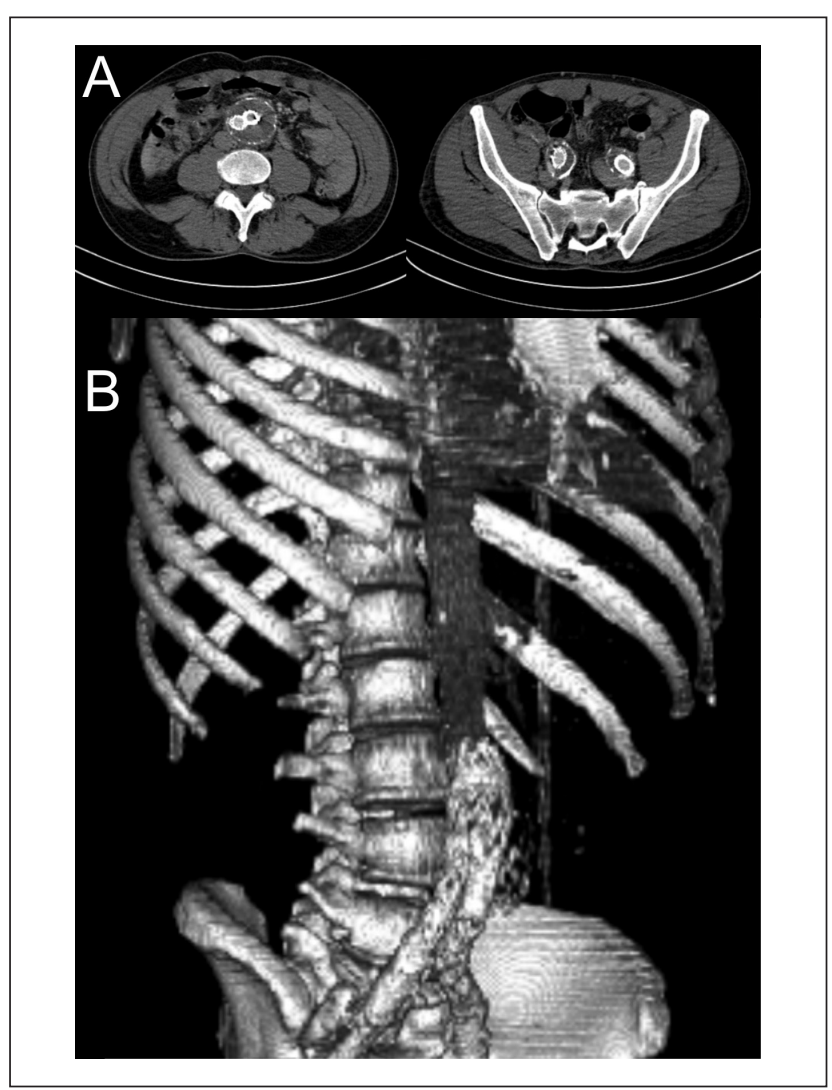

Figure 2 - Post-EVAR axial (A) and 3D reconstruction (B) CT scan, showing adequate positioning of the endograft and no endoleak. 
5-0. The ureter was implanted using Lich-Gregoir technique. Just after the procedure, the kidney started to produce urine. There was no displacement of the endograft during surgery. No complications were observed and the patient was placed on an immunosuppression regimen of mycophenolate, tacrolimus and prednisone. Magnetic resonance imaging angiography (MRI-A) obtained five days after the surgery demonstrated good positioning of the aorto-iliac endograft and adequate perfusion of the renal graft (Figure 3). Creatinine levels dropped from a preoperative value of $6.2 \mathrm{mg} / \mathrm{dL}$ to $1.6 \mathrm{mg} / \mathrm{dL}$ at discharge eight days after transplantation. At office visits, creatinine levels were stable. The four-year follow-up with yearly MRI-A showed good positioning of the endograft without migration or endoleak.

\section{Discussion}

Aneurysmal disease involving aorta and both iliac arteries has not a simple treatment. Either open or endovascular approaches require advanced surgical skills. When associated renal disease is present, the future possibility of a RT must be considered and the ideal treatment must provide adequate conditions for it. Iliac vessels and pelvic space must be preserved.

Our patient was on hemodialysis and had a $5 \mathrm{~cm}$-aortoiliac aneurysm and was in the waiting line for RT. Although EVAR and RT simultaneous performance was described ${ }^{12}$, we decided to perform aneurysm repair first, according to published series ${ }^{3-5}$. The main advantage to treat the aneurysm before RT is to avoid ischemic and nephrotoxic complications in the renal graft, fact that would occur if RT were firstly performed. The choice of EVAR was based on reports of increased morbimortality in open surgery performed in patients like ours ${ }^{1}$. Another important reason is that EVAR does not require extensive dissection of the pelvic space, thus preserving it for a future RT. In fact, we also purposed open surgery, but the patient's choice was EVAR.

In order to completely exclude the aneurysm, covering of both hypogastric artery orifices were necessary. There are several description of ancillary procedures to provide flow to hypogastric arteries in EVAR such as surgical bypass ${ }^{13}$ or endograft associated with crossover femorofemoral bypass $^{14}$. However, these procedures involve respectively pelvic dissection and use of aorto-mono-iliac endograft, which would harm posterior RT. Thus, we chose covering hypogastric artery bilaterally. As in our case, Zander et al. ${ }^{15}$ reported time-limited and insignificant complications with bilateral hypogastric artery occlusion in EVAR. Our patient

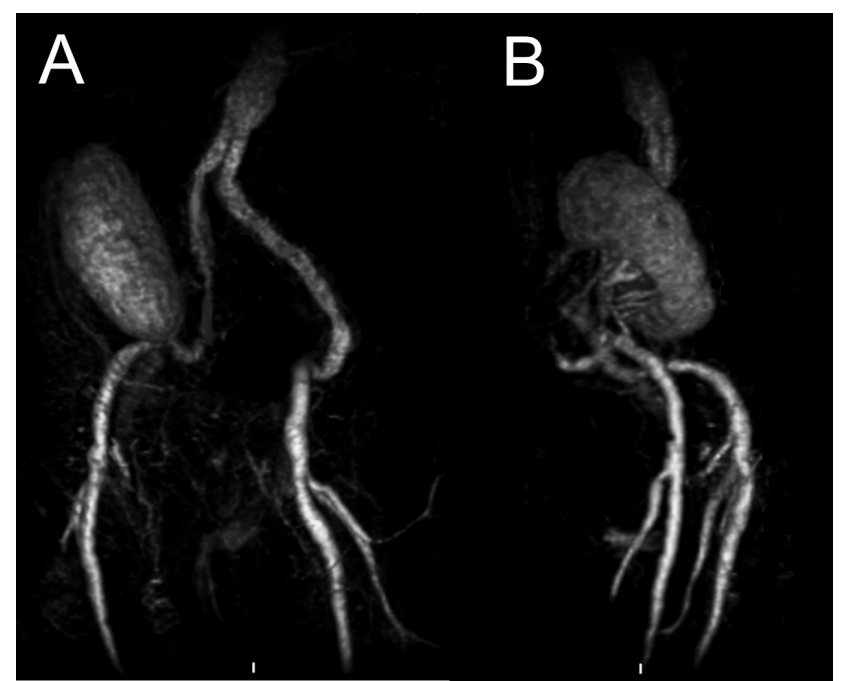

Figure 3 - Post-RT MRI-A, showing good positioning of the aorto-iliac endograft and adequate perfusion of the renal graft.

had only transient thigh paresthesia and full recovery. No bowel ischemia and no buttock claudication were observed. Bilateral hypogastric artery occlusion, although risky, may be acceptable in cases with short therapeutic options, like ours. Recently available branched endograft for iliac arteries $^{16}$ would be suitable solution for preserve hypogastric flow in our case.

During RT after EVAR, possible complications are endograft dislodgment or migration, causing endoleak, and endograft limb thrombosis due to vascular clamping. These complications, which could lead to renal graft loss and EVAR failure, were not observed in our case. Care should be taken not to apply vascular clamps over the endograft.

After RT, MRI-A was used in the follow-up (six months after and then yearly) in order to avoid nephrotoxic effect of iodinated contrast.

\section{Conclusion}

Our experience with aorto-iliac aneurysm corrected by EVAR succeeded by RT concurs with previous reports of aortic aneurysm treated in the same way. In patients with CRF and aorto-iliac aneurysm, EVAR succeeded by RT is feasible and provides good results.

\section{References}

1. Bown MJ, Norwood MG, Sayers RD. The management of abdominal aortic aneurysms in patients with concurrent renal impairment. Eur J Vasc Endovasc Surg. 2005;30:1-11

2. Pedron C, Palis ACM, von Ristow A, et al. Endovascular treatment of abdominal aortic aneurysm in a patient with chronic renal failure. J Vasc Bras. 2006;5:325-30 
3. Brekke IB, Lien B, Sødal G, et al. Aortoiliac reconstruction in preparation for renal transplantation. Transplant Int. 1993;6:161-3.

4. Piquet $P$, Berland $Y$, Coulange C, Olmer M, Mercier C, Rampal M.. Aortoiliac reconstruction and renal transplantation: staged or simultaneous. Ann Vasc Surg. 1989;3:251-6.

5. Gouny P, Lenot B, Decaix B, et al. Aortoiliac surgery and kidney transplantation. Ann Vasc Surg. 1991;5:26-31.

6. Rutherford RB, Krupski WC. Current status of open versus endovascular stent-graft repair of abdominal aortic aneurysm. J Vasc Surg. 2004;39:1129-39.

7. Moon IS, Park SC, Kim SN, et al. Abdominal aortic aneurysm repair in kidney transplant recipients. Transplant Proc. 2006;38:2022-4.

8. Forbes TL, DeRose G, Kribs S, Abraham CZ, Harris KA. Endovascular repair of abdominal aortic aneurysm with coexisting renal allograft: Case report and literature review. Ann Vasc Surg. 2001;15:586-90.

9. Lacombe M. Surgical treatment of aortoiliac aneurysms in renal transplant patients. J Vasc Surg. 2008;48:291-5.

10. Shrestha BM, MCKane WS, Raftery AT. Renal transplantation after endovascular repair of abdominal aortic aneurysm. Transplant Proc. 2007;39:1670-2.

11. George P, Tan HP, Beebe H, Ratner LE. Successful renal transplantation after endovascular bifurcated stent graft repair of an abdominal aortic aneurysm. Transplantation. 2001;72:533-4.

12. Adamec $M$, Matia I, Janousek $L$, et al. Renal transplantation in patients with abdominal aortic aneurysm-a new surgical approach. Transpl Int. 2004;17:647-50.
13. Unno N, Inuzuka K, Yamamoto N, Sagara D, Suzuki M, Konno H. Preservation of pelvic circulation with hypogastric artery bypass in endovascular repair of abdominal aortic aneurysm with bilateral iliac artery aneurysms. J Vasc Surg. 2006;44:1170-5.

14. Bergamini TM, Rachel ES, Kinney EV, Jung MT, Kaebnick HW, Mitchell RA. External iliac artery-to-internal iliac artery endograft: A novel approach to preserve pelvic inflow in aortoiliac stent grafting. J Vasc Surg. 2002;35:120-4.

15. Zander T, Baldi S, Rabellino M, Rostagno R, Isaza B, Llorens R, et al. Bilateral hypogastric artery occlusion in endovascular repair of abdominal aortic aneurysms and its clinical significance. J Vasc Interv Radiol. 2007;18:1481-6.

16. Haulon S, Greenberg RK, Pfaff K, Francis C, Koussa M, West K. Branched grafting for aortoiliac aneurysms. Eur J Vasc Endovasc Surg. 2007;33:567-74.

Correspondence: Department of Surgery and Anatomy of Ribeirão Preto Medical School of USP Avenida Bandeirantes, 3.600 - Campus Universitário CEP: 14048-900 - Ribeirão Preto (SP), Brazi E-mail:mbdalio@gmail.com

Authors's contributions Conception and design: MBD Analysis and interpretation: $M B D, M B$ and $J C$ Data collection: $M B D, E E J$ and NRAD Writing the article: MBD, EE), CEP and HIS Critical revision of the article: CEP, EE Final approval of the article*: MBD Statistical analysis: General responsibility for the study: MBD 